\title{
Composite Silicon Solar Cell Efficiency Simulation Study; Sensitivity to the Absorption Coefficients and the Thickness of Intrinsic Absorber Layer
}

\author{
V. Tudić ${ }^{1}$, M. Marochini' ${ }^{2}$ T. Luke ${ }^{3}$ \\ Ph.D, Department of Mechanical Engineering, Karlovac University of Applied Sciences, Karlovac, Croatia ${ }^{1}$ \\ Student, Department of Mechanical Engineering, Karlovac University of Applied Sciences, Karlovac, Croatia ${ }^{2,3}$
}

\begin{abstract}
In this paper, two silicon solar cells $\mathrm{p}^{+}-\mathrm{i}_{\mathrm{i}}-\mathrm{n}^{+}$with homogenous and heterogeneous intrinsic absorber layers based on hydrogenated amorphous-nanocrystalline-microcrystalline silicon (a-Si:H/nc-Si:H/ $\square$ c-Si:H) have been studied by computer modeling and simulation program (AMPS-1D - Analysis of Microelectronic and Photonic Structures). Various factors that affect cell efficiency performance have been studied such as layers absorption coefficients, band gap and layer thickness up to $1200 \mathrm{~nm}$. It was found that in the case of standard solar cell conditions a layers absorption coefficient has a major contribution to solar cell performance according to measurement on the actual solar cell samples. It is demonstrated that, for homogenous a-Si:H/nc-Si:H intrinsic absorber layer with constant crystal fraction of $\mathrm{Xc}=30 \%$ cell efficiency is higher than in case of heterogeneous intrinsic absorber layer which contains of arbitrary crystal fractions depending of absorber layer thickness. Second case scenario of silicon thin film composite structure is more common in solar cells production according to PECVD and HWCVD deposition technique proven by earlier X-ray diffraction and high resolution electron microscopy measurements.
\end{abstract}

Keywords: Amorphous-nanocrystalline-microcrystalline silicon, absorption coefficients, crystal fraction, efficiency.

\section{INTRODUCTION}

In previous work a semi conducting silicon properties, hetero-junctions and photo effect in intrinsic silicon thin films have been studied, and optical generation and recombination of free carriers had been investigated $[1,2]$. Also, bases physical principles of simple silicon solar cells with accent to amorphous-nanocrystalline layers as permissible composite material for high efficiency solar
cells called third generation layers have been studied. In present work bases principles of pin structure solar cells have been carried out with one dimensional computer modelling programme AMPS-1D. Suggested solar cell model are based to simple pin structure in order to compare simulation results with others in references. Computer modelling programmed allows solar cell parameter calculations and structure design simulations. By varying significant ranges of solar cells parameters such as: illumination spectra, photon flux, absorption coefficient, boundary conditions, front and back contact parameter, general silicon layer parameters as doping and free carrier concentrations, mobility, gap state defect distribution, I-V characteristic, fill factor (FF), and efficiency $(\square)$ of solar cell can be determinate. In this work a few simulation groups are carried out with homogenous and heterogeneous intrinsic layers of permissible high efficiency solar cells. Calculated solar cells efficiency of modelled single and multilayer absorber structures were graphically presented and discussed.

A goal of this work is quite ambitious in its choice to suggest possible application of such a-Si:H/nc-Si:H/ $\square$ c-Si:H film layers as active part in solar cells in a typical pin solar cell in respect to overall performance. A detailed comparison of calculated data extracted from defined model suggest optimal absorber layer thickness of composite silicon solar cell and will inevitably lead to a better understanding of effective solar cell thickness, respectability.

\section{INTRINSIC LAYER MICROSTRUCTURE}

Amorphous-nanocrystalline silicon (a-nc-Si) films of few hundred nanometers in thickness consist of a matrix of amorphous silicon with embedded silicon crystals of nanometric dimensions [3, 4]. This material has improved properties with respect to pure amorphous $\mathrm{Si}(\mathrm{a}-\mathrm{Si})$, microcrystalline $\mathrm{Si}(\square \mathrm{c}-\mathrm{Si}$ ) and bulk crystalline $\mathrm{Si}$ (c-Si) owning quantum confinement effect [5]. When compared to amorphous silicon, nc-Si has better electrical transport characteristic [6], possibility to tailor the optical band gap [7] and resistance to light induced degradation [8].

Micro-crystalline silicon ( $\square \mathrm{c}-\mathrm{Si}$ ) films of 1-2 micrometers in thickness consist of formation of small crystal aggregates in deeper layers and large grains/columns up to film surface $[9,10]$.

On the other hand micro-crystalline $\mathrm{Si}(\square \mathrm{c}-\mathrm{Si}$ ) and bulk crystalline $\mathrm{Si}$ (c-Si) compared to $\mathrm{nc}-\mathrm{Si}$ has better conductivity along crystal grains according to higher free carrier mobility and less numbers of brain boundaries. Therefore $\square \mathrm{c}-\mathrm{Si}$ layers has better electrical transport characteristic compared to a-nc-Si [11]. 
The main advantage of nc-Si in comparison with crystalline device simulation was published in literature [3, 4]. silicon is its higher absorption, which allows efficient solar Amongst others, sample number two (K2) is chosen in cells in thin film designed device. This material could be simulation modeling because of convenient value of its fraction of "small crystals", expected to show effect of band gap energy $\left(E_{\mathrm{g}}=1.82 \mathrm{eV}\right)$ caused by lower crystalline increase in optical gap due to quantum confinement fraction (vol. 30\%). predictable according to effective mass theory or quantum dots.

As a result of PECVD and HWCVD deposition techniques micro-crystalline silicon thin films typically forms a microstructure presented in Figure 1. It has a complicated microstructure, mixture of crystalline silicon (c-Si) grains, grain boundaries and/or amorphous-nano-crystalline hydrogenated silicon (a-nc-Si:H) often called "tissue".

Approach followed in this paper is to compare on as wide as possible range of a-nc- $\square \mathrm{c}-\mathrm{Si}: \mathrm{H}$ layer-samples the microstructure (grain size, crystallinity and roughness) with the optical and transport properties and to find overall performance. We have used the fact that a-nc- $\square$ c-Si:H microstructure changes with the thickness of sample [11]. AFM and SEM micrographs of some authors [10, 12] reveals surface morphology of micro-crystalline silicon films thickness as sample of 1.4 micrometers published in [12].

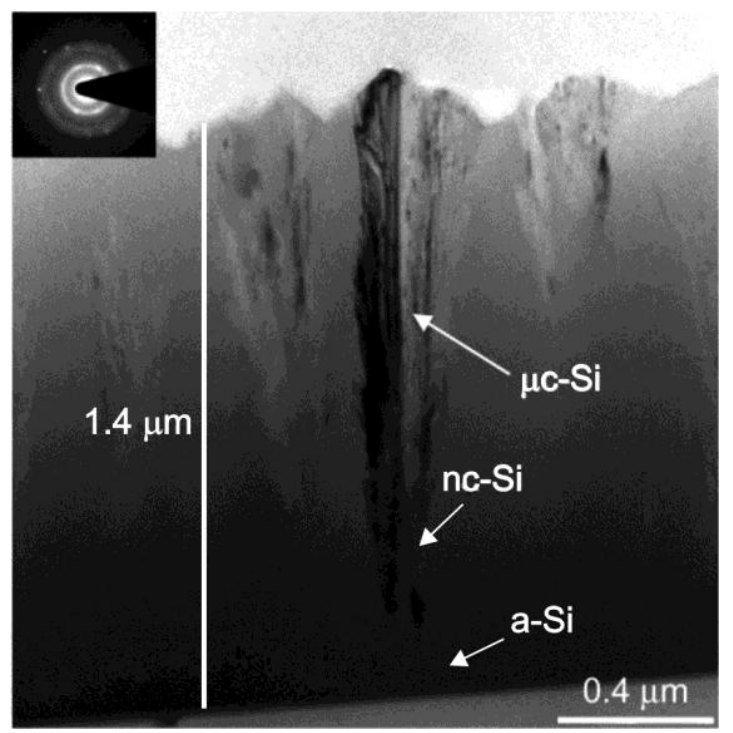

Figure 1.Typical SEM micrograph of composite silicon (anc- $\square$ c-Si:H) thin film $1.4 \square$ m of thickness produced with Cat-CVD (Hot Wire CVD) technique, published in [12].

Large complexity of microstructure in hydrogenated microcrystalline silicon and existence of tissue with at least two different sizes of crystallites determine the optical properties and therefore modeled complex free carrier mobility based on mechanism of transport.

\section{OPTICAL PROPERTIES}

The optical properties of composite silicon thin films strongly depend on the production conditions and determination of the structural properties of the thin film. The spectra of absorption coefficient, $\square(E)$, of typical nc-Si thin film calculated from transmittance by Fourier transform photocurrent spectroscopy (FTPS) and photo deflection spectroscopy (PDS) is shown in Figure 2. Absorption coefficient data we used in our calculation and

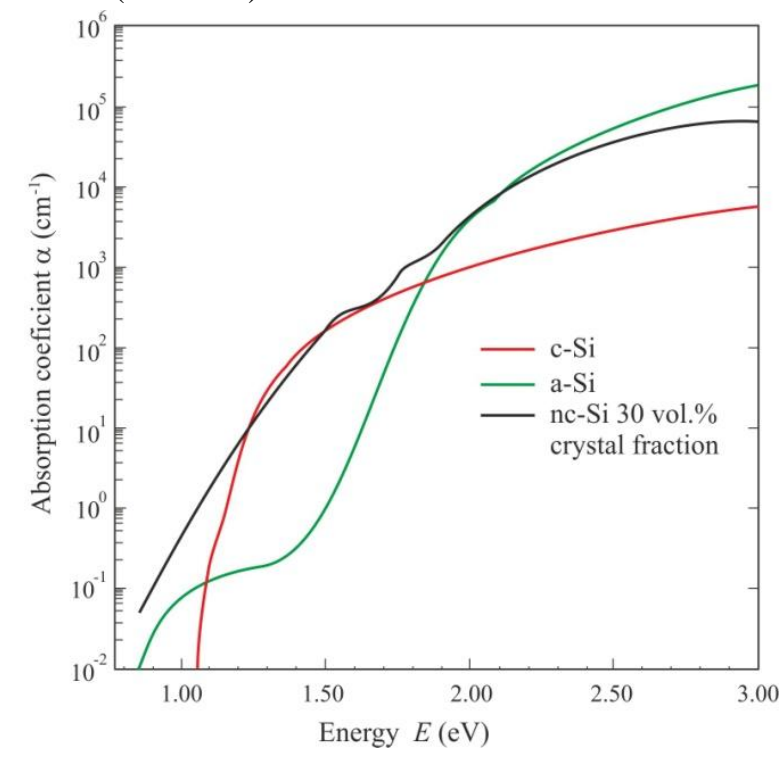

Figure 2. Distribution of absorption coefficient of nc-Si (black line), a-Si (green line) and c-Si (red line) calculated from FTPS and PDS [4].

\section{IV.SIMULATION MODEL}

Computer modeling software AMPS-1D can simulate all modeled semiconductor and photovoltaic device structures. In the present version of AMPS-1D user can chose one of two different calculation models: Density of States (DOS approach) and Carrier Lifetime Model (CLM). DOS approach is more suited for silicon amorphous and nanocrystalline thin films layers due to large defect densities in midgap states $[13,14]$.

Model of photovoltaic device can be simulated throe optical and material parameters on device designed structure. Material and optical properties affect electrical parameters in tree differential equations in correlation: the Poisson's equation, electron continuity equation and hole continuity equation. Those tree equations are solved simultaneously under non-equilibrium steady-state conditions (i.e., under the effect of light, voltage bias or both) by using method of finite differences and NewtonRaphson technique. The used equations are:

Poisson's equation,

$$
\frac{\rho(x)}{\varepsilon}=\frac{\partial \Psi(x)}{\partial x}
$$

Electron continuity equation,

$$
\frac{1}{q} \frac{\partial J_{n}(x)}{\partial x}=R(p(x), n(x))-G_{o p}(x)
$$

And hole continuity equation,

$$
\frac{1}{q} \frac{\partial J_{p}(x)}{\partial x}=G_{o p}(x)-R(p(x), n(x))
$$


All carriers in semiconductor layer can be described by net charge density value $\rho(x)$, expressed like

$$
\rho(x)=q\left[p(x)-n(x)+p_{T}(x)-n_{T}(x)+N_{A}-N_{D}\right]
$$

And the present electrostatic field $E$ is defined as

$$
E=\frac{\partial \Psi(x)}{\partial x}
$$

In equation $\square$ is the dielectric constant, $E$ is electrostatic field, $\square(x)$ represents the position of energy in the local vacuum level, $x$ is position in the device, $n$ and $p$ the extended states density in conduction and valence band, respectively, $p_{T}$ and $n_{T}$ the trapped hole and electron population density, $N_{A}$ acceptor doping density, $N_{D}$ the donor doping density, if exists, the $q$ the electron charge, $R(x)$ the recombination rate, $G_{\mathrm{op}}(x)$ the optical generation rate of free electron-hole pair, $J_{n}$ and $J_{p}$ the electron and hole current density, respectively. The term $R(x)$ is the net recombination rate resulting from band-to-band (BTB) direct recombination and Shockley-Read-Hall (SRH) indirect recombination traffic through gap states. The model used in AMPS for indirect recombination assumes that the traffic back and forth between the delocalized bands and the various types of delocalized gap states is controlled by SRH, capture and emission mechanisms. Since AMPS has the flexibility to analyze device structures which are under light bias (illumination) as well as voltage bias, the continuity equations include the term $G_{\text {op }}(x)$ which is the optical generation rate as a function of $x$ due to externally imposed illumination.

Generally, the three state variables completely define the state of a device: local vacuum energy level $\square$ and the quazi-Fermi levels $E_{\mathrm{Fp}}$ and $E_{\mathrm{Fn}}$. Once those tree dependent variables are calculated as a function of position in device, all other parameter can be determinate as its function. In thermodynamic equilibrium, the Fermi level is a constant as a function of position and hence the tree equations (1-3) essentially reduce to Poisson's equation. Therefore, local vacuum energy level $\square$ is the only variable to solve in thermodynamic equilibrium.

Otherwise, in non-thermodynamic equilibrium steady-state, a system of three correlated non-linear second order differential equations in the tree unknowns $\left(\square, E_{\mathrm{Fp}}, E_{\mathrm{Fn}}\right)$ is obtained. Further calculation need six boundary conditions, two for each dependent variable. The first two boundary conditions are modified versions of the ones used for solving Poisson's equation in thermodynamic equilibrium:

$$
\Psi(0)=0-\chi(L)-\varphi_{b L}+\chi(0)-V
$$

And

$$
\Psi(L)=0
$$

Where $L$ is the total length of the modeled device, $\square \square \square \square \square \square \square \square L \square$ are the electron affinities at $x=0$ and $x=L$, respectively and $V$ is applied voltage. Zero value of local vacuum energy level $\square \square$ is at boundary point $x=L$. The four other boundary conditions are obtained from imposing constraints on the currents at the boundaries at $x=0$ and $x=L$. These constraints force the mathematics to acknowledge the fact that the currents must cross at $x=0$ and $x=L$ (contact position) by either thermionic emission or interface recombination. Mathematically expressed current values at boundaries:

$$
\begin{aligned}
& J_{n}(0)=q S_{n 0}\left[n(0)-n_{0}(0)\right] \\
& J_{p}(0)=q S_{p 0}\left[p(0)-p_{0}(0)\right] \\
& J_{n}(L)=q S_{n L}\left[n(L)-n_{0}(L)\right] \\
& J_{p}(0)=q S_{p L}\left[p(L)-p_{0}(L)\right]
\end{aligned}
$$

Where $S_{\mathrm{n} 0} \square \square S_{\mathrm{p} 0}$ are surface recombination velocities for electrons and holes respectively at the $x=0$ interface and the quantities are the corresponding velocities at the $x=L$ interface. Strongly limited by thermionic emission largest value of recombination velocities cannot over cross $10^{7} \mathrm{cms}^{-1}$. In equations (8-9) $\mathrm{n}(0)$ and $\mathrm{p}(0)$ are the electron and hole density at $x=0, \mathrm{n}(L)$ and $\mathrm{p}(L)$ are the same values at $x=L$. Analogy, $\mathrm{n}_{0}(0)$ and $\mathrm{p}_{0}(0), \mathrm{n}_{0}(L)$ and $\mathrm{p}_{0}(L)$ are the electron and hole density at the thermodynamic equilibrium at boundaries $x=0$ and $x=L$, respectively. Now, when all conditions are defined, simultaneously calculation of $\square$, $E_{\mathrm{Fp}}$ and $E_{\mathrm{Fn}}$ can be obtained. The model used in our simulation for gap states consist of two exponential tail states distributions and two Gaussian distributions of deep defects states [13].

\section{SOLAR CELL PARAMETERS}

In this paper we have simulated two types of single junction solar cells both with absorber layer thickness of $1200 \mathrm{~nm}$. The first type have the standard pin structure with one homogenous absorber: (p-) a-Si:H/ (i-) a-Si:H/ (n-) a$\mathrm{Si}: \mathrm{H}$ and the second type with inhomogeneous absorber has a multi-layer structure with 9 intrinsic absorbers with various structural and therefore optical properties (Fig.2). Thickness of layers for standard pin structure is as follows: (p-) $8 \mathrm{~nm} /(\mathrm{i}-)$ 1400nm/ (n-) $15 \mathrm{~nm}$.

We propose an implementation of chemically textured zinc-oxide $\mathrm{ZnO}$ : $\mathrm{Al}$ film or $\mathrm{SnO}_{2}$ as a front $\mathrm{TCO}$ in our $\mathrm{p}$-i-n solar cells, and in combination with $\mathrm{Ag}$ as a textured back reflector-enhancing dielectric layer for additional efficiency. Such modeled cells exhibit excellent optical and light-trapping properties demonstrated by high short-circuit current densities.

\section{A. Boundary conditions}

The tree governing equations (1), (2) and (3) must hold every position in the device and the solution to those equations involves determining the state variables $\square(x)$ $E_{\mathrm{Fp}}(x)$ and $E_{\mathrm{Fn}}(x)$. Non-linear and coupled equations cannot be solved analytically, numerical methods must be utilized. Boundary conditions must be imposed on the sets of equations. These are expressed in terms of conditions on the local vacuum level and the currents at the contacts. To be specific the solution to equations (1), (2) and (3) must satisfy the boundary conditions (6-11). In computer modeling program AMPS-1D $\square(0)$ is PHIB0, $\square(\mathrm{L})$ is PHIBL, $S$ is recombination speed for holes and electrons depending on carrier position. Parameter RF is reflection coefficient at $x=0, \mathrm{RB}$ is reflection coefficient at $x=L$. In 
actual situation RF is parameter of lost photon flux transmitting throe glass substrate and TCO layer. Measurements of solar cells internal optical loses (in visible spectrum) showing wavelength ( $\square$ ) or energy dependence $\square \square[5,6,15]$. Reflection coefficient RB depends of optical characteristics of back electrode which acts as an optical mirror and efficient light trapping. The properties of the front contact and back contact used as the model parameters are shown in Table I.

TABLE I. Boundary conditions in AMPS-1D: PHIB0 is $\square(0)$ at $x=0$; PHIBL is $\square(\mathrm{L})$ at $x=\mathrm{L}$ (total device length); SN0-SNL-SP0-SPL are surface recombination speeds at $x=0$ and $x=\mathrm{L}(\mathrm{N}=$ electron, $\mathrm{P}=$ hole $) ; \mathrm{RF}$ is reflection coefficient at $x=0 ; \mathrm{RB}$ is reflection coefficient at $x=\mathrm{L}$.

\begin{tabular}{|c|c|}
\hline Front Contact & Back Contact \\
\hline $\mathrm{PHIB} 0=1.730 \mathrm{eV}$ & $\mathrm{PHIBL}=0.120 \mathrm{eV}$ \\
\hline $\mathrm{SN} 0=1 \times 10^{7} \mathrm{~cm} / \mathrm{s}$ & $\mathrm{SNL}=1 \times 10^{7} \mathrm{~cm} / \mathrm{s}$ \\
\hline $\mathrm{SP} 0=1 \times 10^{7} \mathrm{~cm} / \mathrm{s}$ & $\mathrm{SPL}=1 \times 10^{7} \mathrm{~cm} / \mathrm{s}$ \\
\hline $\mathrm{RF}=0.250$ & $\mathrm{RB}=0.600$ \\
\hline
\end{tabular}

\section{B. Solar cells design}

Second type model of solar cell with multilayer absorbers will be detailed explained in this part. Solar cell design in fact represents a-Si:H/nc-Si:H/ $\square \mathrm{c}-\mathrm{Si}: \mathrm{H}$ inhomogeneous intrinsic absorber of pin silicon solar cell with thickness of 1200nm (Fig.3).

Design complies of multi-layer structure with 9 individual intrinsic absorbers arbitrary modeled thickness with various structural and optical properties (Fig.4). Solar cell model structure is as follows:

Transparent Conductive Oxide (TCO) is solar cell front contact for collecting holes $(0.3 \square \mathrm{m})$, a-Si:H (p-1) window layer $(8 \mathrm{~nm})$, a-nc-Si:H absorbers $\mathrm{i}_{1}-2 / \mathrm{i}_{4}-5$ (100nm), nc$\mathrm{Si}: \mathrm{H}$ absorber $\mathrm{i}_{5}-6 / \mathrm{i}_{6}-7$ (100nm), nc- $\square \mathrm{cSi}: \mathrm{H}$ absorber $\mathrm{i}_{7}-$ 8/i ${ }_{8}-9$ (200nm), $\square$ cSi:H absorber $\mathrm{i}_{9}-10$ (400nm), a-Si:H (n11) back layer $(15 \mathrm{~nm})$, Aluminum-doped Zinc Oxide (AZO) is reflection layer $(0.1 \square \mathrm{m}), \mathrm{Ag}$ as a textured back reflector (0.5-2 $\square \mathrm{m})$, Aluminum back contact electrode (2$3 \mathrm{~mm})$.

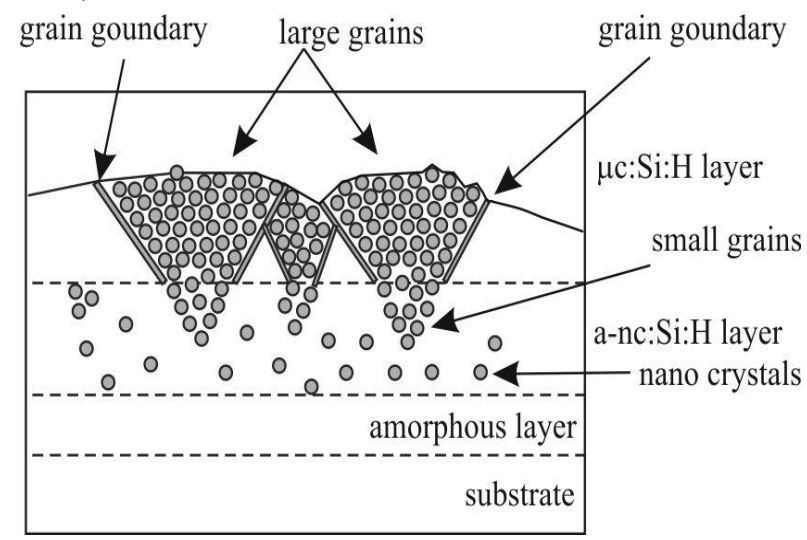

Figure 3.Drawing of composite silicon (a-nc- $\square$ c-Si:H) thin film cross section of $1.2 \square \mathrm{m}$ thickness; it consists of multi layers with different structure and absorption properties.

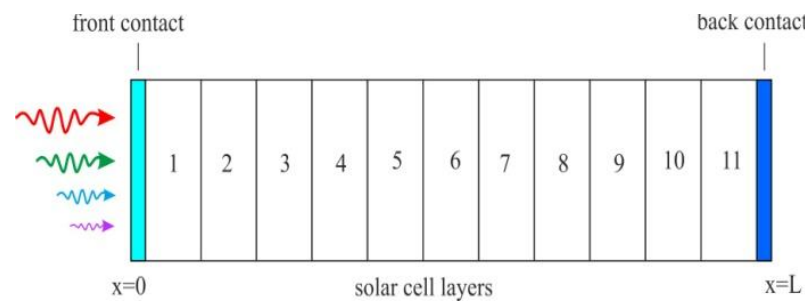

Figure 4.Model of solar cell with multi layer absorbers: (p) is layer $1,(n-)$ is layer 11 and layers 2-10 are 9 individual intrinsic absorbers with various thicknesses, structural and optical properties [18].

The input parameters of all modeled solar cell layers in order to simulate efficiency properties of actual solar cell are not given in complete because of complexity. Published selected mobility parameters are taken from references $[16,17]$ and absorption coefficients from a-nc$\mathrm{Si}: \mathrm{H}$ and c-Si:H samples. We used standard boundary conditions and standard global illumination conditions (Table I), air-mass $1 / \cos \square$ (AM1.5 spectrum), $1000 \mathrm{~W} / \mathrm{m}^{2}$ at $300 \mathrm{~K}$ temperature reference.

\section{Absorption coefficients}

One set of absorption coefficient data we used in our calculation and device simulation was measured on samples and published in literature [3,9]. It is coefficient for a-nc-Si:H sample and c-Si:H silicon layer. Amongst others, a-nc-Si:H sample is chosen in this modeling because of convenient value of its band gap energy $\left(E_{\mathrm{g}}=1.82 \mathrm{eV}\right)$ caused by lower crystalline fraction (vol. $30 \%)$, layer thickness $(100 \mathrm{~nm})$ and calculated DC conductivities and free carrier mobility [2].

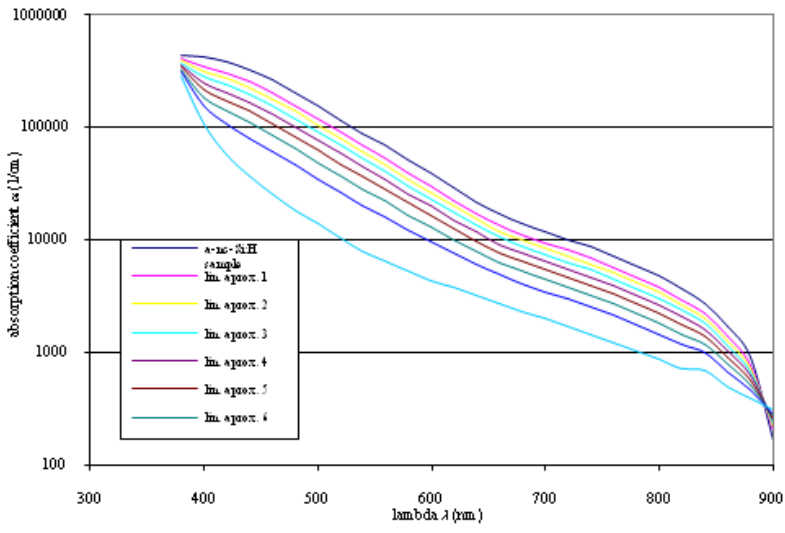

Figure 5. Absorption coefficients $\square(\square)$ of nine absorber layers in modeled solar cell [18].

Presented modeled device of solar cell (Fig.4) consists of 9 absorber layers with 2 actual absorption coefficients and 7 approximated absorption coefficients between a-nc-Si:H (front) and c-Si:H (back) silicon layer. Therefore, absorption coefficients of each individual absorber layer are modeled and proposed by linear approximationsuperposition according to different microstructure (Fig.3) throe solar cell variable length (parameter $x$ ). According to layer thickness or calculated length $x$ each individual absorber layer has different superposition ratio of absorption coefficients between a-nc-Si:H and c-Si:H layers as it is in actual solar cell. For example: absorption layer 2 (i1-) in modeled solar cell is a-nc-Si:H actual 
sample with measured absorption coefficient, absorption layer 3 (i2-) is a-nc-Si:H modeled layer with proposed absorption coefficient in ratio a-nc-Si/c-Si $(0,25 / 0,75)$, absorption layer 3 (i2-) is a-nc-Si:H modeled layer with proposed absorption coefficient in ratio a-nc-Si/ $\square$ c-Si $(0,35 / 0,65)$, ect. Last layers are: absorption layer 9 (i8-) in modeled solar cell is nc- $\square$ c-Si:H layer with proposed absorption coefficient in ratio $\mathrm{nc}-\mathrm{Si} / \square \mathrm{c}-\mathrm{Si}(0,85 / 0,15)$ and absorption layer 10 (i9-) is $\square \mathrm{c}-\mathrm{Si}: \mathrm{H}$ actual sample with measured absorption coefficient (Fig. 5).

\section{Free carriers mobility}

In mixed phases silicon thin film layers transport mechanism strongly depends of carrier mobility $\square \square\left(\mathrm{cm}^{2}\right.$ $\mathrm{V}^{-1} \mathrm{~s}^{-1}$ ). Electron $\square_{\mathrm{n}}$ and hole $\square_{\mathrm{p}}$ mobility have dependence to crystal lattice temperature also donor-like and acceptorlike doped concentrations [18], defect density [11], DC conductivity [19], suggesting electron mobility at temperature of $300 \mathrm{~K}$ maximal values of $1250 \mathrm{~cm}^{2} \mathrm{~V}^{-1} \mathrm{~s}^{-1}$ and hole mobility maximal values of $400 \mathrm{~cm}^{2} \mathrm{~V}^{-1} \mathrm{~s}^{-1}$ in bulk (intrinsic) crystalline silicon.

For electron mobility at temperature of $300 \mathrm{~K}$ in a-Si:H intrinsic silicon layers in simulation values are modeled as follows: $\left(\mathrm{M}_{\mathrm{UN}}\right) 10-20 \mathrm{~cm}^{2} \mathrm{~V}^{-1} \mathrm{~s}^{-1},\left(\mathrm{M}_{\mathrm{UP}}\right) 2-4 \mathrm{~cm}^{2} \mathrm{~V}^{-1} \mathrm{~s}^{-1}$. For a-nc-Si:H thin film layers values are: $\left(\mathrm{M}_{\mathrm{UN}}\right)$ 100-250 $\mathrm{cm}^{2} \mathrm{~V}^{-1} \mathrm{~s}^{-1},\left(\mathrm{M}_{\mathrm{UP}}\right) 8-60 \mathrm{~cm}^{2} \mathrm{~V}^{-1} \mathrm{~s}^{-1}$; for nc-Si:H layers $\left(\mathrm{M}_{\mathrm{UN}}\right)$ 400-650 $\mathrm{cm}^{2} \mathrm{~V}^{-1} \mathrm{~s}^{-1}$, (MUP) 100-180 $\mathrm{cm}^{2} \mathrm{~V}^{-1} \mathrm{~s}^{-1}$, for $\mathrm{nc}-$ $\mathrm{Si}: \mathrm{H} / \square \mathrm{c}-\mathrm{Si}: \mathrm{H}$ layers $\left(\mathrm{M}_{\mathrm{UN}}\right) 800-1000 \mathrm{~cm}^{2} \mathrm{~V}^{-1} \mathrm{~s}^{-1},\left(\mathrm{M}_{\mathrm{UP}}\right)$ 200-300 $\mathrm{cm}^{2} \mathrm{~V}^{-1} \mathrm{~s}^{-1}$; and for $\square \mathrm{c}-\mathrm{Si}: \mathrm{H}$ layers $\left(\mathrm{M}_{\mathrm{UN}}\right)$ 1200$1250 \mathrm{~cm}^{2} \mathrm{~V}^{-1} \mathrm{~s}^{-1},\left(\mathrm{M}_{\mathrm{UP}}\right) 300-400 \mathrm{~cm}^{2} \mathrm{~V}^{-1} \mathrm{~s}^{-1}$.

\section{SIMULATION RESULTS AND DISCUSION}

The performance of modeled solar cells was analyzed in respect to the current density $\left(J_{\mathrm{SC}}\right)$ and efficiency $(\square)$ by incorporating the layer parameters into AMPS- 1D.

First pin structure consists of homogenous intrinsic a-nc$\mathrm{Si}: \mathrm{H}$ absorber in thickness of $1200 \mathrm{~nm}$ with constant crystal fraction of $\mathrm{Xc}=30 \%$. In second pin structure with the same thickness we modeled an inhomogeneous intrinsic absorber which consists of 9 individual homogenous layers with different optical and electrical properties suggesting experimentally proven structure in-homogeneity. In standard simulation conditions defined earlier for the first structure simulation results shown predictable curves and maximal value of $J_{\mathrm{SC}}=17.421 \mathrm{~mA} / \mathrm{cm}^{2}$ at $1200 \mathrm{~nm}$ of absorber thickness and maximal efficiency of $\square \square=13.992 \%$ at $935 \mathrm{~nm}$ (Fig.6.). In second modeled structure calculated values are different: $J_{\mathrm{SC}}=14.781 \mathrm{~mA} / \mathrm{cm}^{2}$ at $1200 \mathrm{~nm}$ of absorber thickness and maximal solar cell efficiency of $\square \square=12.32 \%$ at $492 \mathrm{~nm}$ (Fig.7.).

For both type of modeled devices simulation promotes typically exponentional rise of current density in the first $300 \mathrm{~nm}$ of thickness according to excellent photon absorption and collection of photo-generated electron-hole pairs in absorber structure with 10-100ns free carrier life time in first few hundred nanometers of thickness of a-nc$\mathrm{Si}: \mathrm{H}$ tissue. Current densities in our simulation had never reached its calculated maximum in both cases. In first solar cell model simulation improvement in efficiency is supported by at least one order of magnitude better absorption in a-nc-Si:H homogenous absorber, good conductivity and therefore high free carrier mobility. Also, efficiency curve points to saturation at $600 \mathrm{~nm}$ and its decrease at thicknesses higher then 900nm. Calculated solar cell performances in first model simulation are likely expected according to physical nature of photo-generation and recombination of electron-hole pairs in intrinsic silicon with controlled general silicon layer parameters as doping and free carrier concentrations, mobility and gap state defect distribution.

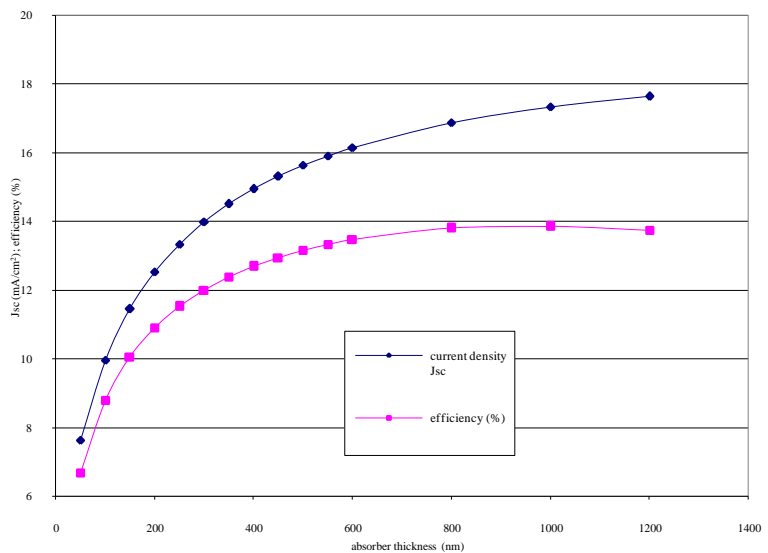

Figure 6. Graphical presentation of calculated solar cell current density $\mathrm{J}_{\mathrm{SC}}\left(\mathrm{mA} / \mathrm{cm}^{2}\right)$ and efficiency $\square \square(\square)$ in case of homogeneous absorber with crystal fraction of $30 \%$.

Second pin model solar cell design implies experimentally proven structure in-homogeneity of silicon CVD thin films. Absorption coefficient decreases drastically throe structure instead of increasing of free carrier mobility according to tissue structure changes. As a result of different optical and electrical properties in the structure layers of the inhomogenous solar cell calculated performance is expectable. Optimum efficiency of $\square \square=12.32 \%$ is reached at $492 \mathrm{~nm}$ (Fig.7.) and current density of $J_{\mathrm{SC}}=12.21 \mathrm{~mA} / \mathrm{cm}^{2}$ exists at the same absorber thickness.

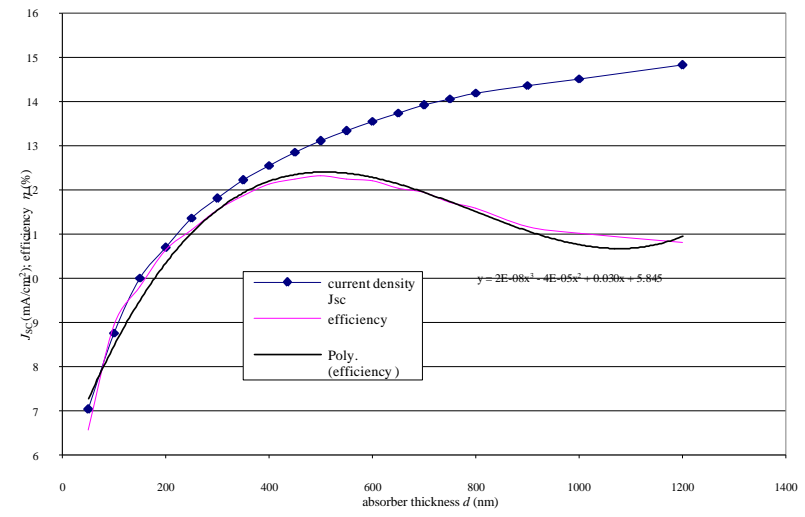

Figure 7. Graphical presentation of calculated solar cell current density $\mathrm{J}_{\mathrm{SC}}\left(\mathrm{mA} / \mathrm{cm}^{2}\right)$ and efficiency $\square(\square)$ in case of inhomogeneous absorber presented with 9 different absorber layers.

In Figure 7 additional curve (black line) represents third degree Polynomial of efficiency curve suggesting efficiency calculation in any absorber thickness (absorber dimension $x$ ). 


\section{CONCLUSION}

In this study we have simulated two types of single junction solar cells with absorbers of a-nc-Si:H and a$\mathrm{Si}: \mathrm{H} / \mathrm{nc}-\mathrm{Si}: \mathrm{H} / \square \mathrm{c}-\mathrm{Si}: \mathrm{H}$ tissues. A series of simulations were carried out in order to calculate the efficiency of modeled solar cell by varying the properties each of layers in the range published in the literature. The obtained results show clearly that the cells reach its optimum efficiency at different thicknesses. In case of homogenous silicon a-nc$\mathrm{Si}: \mathrm{H}$ tissue expected efficiency is around $14 \%$ and this value is in correlation with crystal fraction, absorption coefficient and free carrier mobility, respectively. In case of in-homogenous a-Si:H/nc-Si:H/ $\square$ c-Si:H absorber expected efficiency is around $12 \%$ and lower strongly depending of structure characteristic.

The observed silicon layers specificity in the optical and electrical properties can be explained as a consequence of thin film deposition techniques forming regions of nano and micro crystals with arbitrary concentrations in amorphous matrix to determine free carrier transport model.

However, the goal of this work is quite ambitious in its choice to enable a preventive efficiency calculation of composite silicon solar cells before its production if deposition techniques are known, constant and stabile. By building of experimental data matrix concerning arbitrary concentrations of crystals and thickness of deposition layers it could be possible to predict solar cell efficiency using for example a principal method and third degree Polynomial approximation such as the one derived here.

\section{REFERENCES}

[1] D. Gracin, K. Jurajić, I. Djerdj, A. Gajović, S. Bernstorff, V. Tudić, M. Čeh, "Amorphous-nanocrystalline silicon thin films for single and tandem solar cells", $14^{\text {th }}$ Photovoltaic Technical Conference Thin Film \& Advanced Silicon Solutions, June, 2012, Aix en Provence, France.

[2] V. Tudić, "AC Impedance Spectroscopy of a-nc-Si:H Thin Films", Scientific Research Engineering, July, 2014, vol. 6, No. 8, pp. 449461. doi: 10.4236/eng.2014.68047.

[3] J. Sancho-Parramon, D. Gracin, M. Modreanu, A. Gajovic, "Optical spectroscopy study of nc-Si-based p-i-n solar cells", Solar Energy Materials \& Solar Cells 93, 2009, pp. 1768-1772.

[4] D. Gracin, A. Gajović, K. Juraić, J. Sancho-Parramon, M. Čeh: "Correlating Raman-spectroscopy and high-resolution transmission-electron-microscopy studies of amorphousnanocrystalline multilayered silicon thin films"; Thin Solid Films 517, 2009, vol. 18, pp. 5453-5458

[5] A. M. Ali, "Origin of photoluminescence in nanocrystalline $\mathrm{Si}: \mathrm{H}$ films", Journal of Luminescence, 2007, vol. 126, pp. 614-622.

[6] A. V. Shah, J. Meier, E.Vallat-Sauvain, N. Wyrsch. U. Kroll, C. Droz, U. Graf, "Material and solar cell research in microcrystalline silicon“, Solar Energy Materials \& Solar Cells, 2003, vol. 78, pp. 469-491.

[7] A. M. Ali, "Optical properties of nanocrystalline silicon films deposited by plasma-enhanced chemical vapor deposition", Optical Materials, 2007, vol. 30, pp. 238-243.

[8] S. Hazra, S. Ray, "Nanocrystalline silicon as intrinsic layer in thin film solar cells, Solid State Commun., 1999, vol. 109, pp. 125-128.

[9] D. Gracin, A. Gajović, K. Juraić, J. Sancho-Parramon, M. Čeh: "Correlating Raman-spectroscopy and high-resolution transmission-electron-microscopy studies of amorphousnanocrystalline multilayered silicon thin films", Thin Solid Films, 2009, vol. 517, Is. 18 , pp. 5453-5458.

[10] Kočka, J., Stuchlíkova, H., Stuchlík, J., Rezek, B., Mates, T., Švrcek, V., Fojtík, P., Pelant, I., Fejfar, A., "Microcrystalline silicon - relation of transport and microstructure“, Solid State Phenomena, 2001, Vol. 80-81, pp. 213-224.

[11] Kočka, J., Stuchlíkova, H., Stuchlík, J., Rezek, B., Mates, T., Švrcek, V., Fojtík, P., Pelant, I., Fejfar, A., Model od transport in Micro-crystalline silicon“, Journal of Non-Crystalline Solids, 2002, Vol. 299-302, pp. 355-359.

[12] Moutinho, H.R., Jiang, C.-S., Perkins, J., Xu, Y., Nelson, B.P., Jones, K.M., Romero, M.J., Al-Jassim M.M., "Effects of dilution ratio and seed layer on the crystallinity of microcrystalline silicon thin films deposited by hot-wire chemical vapor deposition“, Thin Solid Films, 2003, Vol. 430, Issues 1-2, pp. 135-140.

[13] A. Belfar, R. Mostefaoui, "Simulation of n1-p2 Microcrystalline Silicon Tunnel Junction with AMPS-1D in a-SiC:H/ $\square$ c-Si:H Tandem Solar Cell, Journal of Applied Science, 2011, pp. 10.3923.

[14] S. Tripati, R. O. Dusane, "AMPS-1D simulation studies of electron transport in mc-SI:H thin films", Journal of Non-Crystalline Solids, 2006, vol. 352, pp. 1105-1108.

[15] R. H. Franken, R. L. Stolk, H. Li, C. H. M. Van der Werf, J. K. Rath, R. E. I. Schropp, "Understanding light trapping by light scattering textured back electrodes in thin film n-i-p-type silicon solar cells“, Journal of Applied Physics, 2007, vol. 102, pp. 014503.

[16] D. Stieler, V. D. Dalal, K. Muthukrishnan, M. Noack, E. Schares, "Electron mobility in nanocrystalline devices", Journal of Applied Physics, 2006, vol. 100, doi: 10.1063/1.2234545.

[17] B. Van Zeghbroeck, "Mobility Carrier Transport, Principles of semiconductor devices“, ECEE University of Colorado, 2011.

[18] V. Tudić, "Modeling of Electric characteristics of the photovoltaic amorphous-nanocrystalline silicon cell“, doctoral thesis, Faculty of Electrical Engineering and Computing, 2014, Zagreb, Croatia, 245 $\mathrm{pp}$

[19] K. Shimakawa, "Photo-carrier transport in nanocrystalline silicon films“", Journal of Non-Crystalline Solids, 2006, vol. 352, Issues 929 , pp. 1180-1183. 